\title{
CHP-HER-2 Peptide Vaccine
}

National Cancer Institute

\section{Source}

National Cancer Institute. CHP-HER-2 Peptide Vaccine. NCI Thesaurus. Code C62597.

A peptide vaccine, containing nanoparticles of cholesteryl hydrophobized pullulan (CHP) complexed with the tumor-associated antigen HER-2/neu (ErbB-2), with potential antineoplastic activity. Her-2/neu, a member of the epidermal growth factor receptor (EGFR) family of tyrosine kinases, is overexpressed in various tumors, including breast, ovarian, and gastric cancers. Vaccination with CHP-HER-2 peptide vaccine may stimulate the host immune system to mount a humoral as well as a cytotoxic $\mathrm{T}$-cell response against tumor cells expressing the HER-2/neu antigen. This results in an inhibition of tumor cell proliferation and tumor cell death. The self-aggregating CHP, composed of a pullulan backbone and cholesterol branches, forms stable colloidal nanoparticles in water. 